\title{
Editorial
}

\section{The Journal of Applied Oral Science will soon use a new online submission system}

Dear Readers, Contributors and Reviewers,

The Scientific Electronic Library (SciELO), with the support of the São Paulo Research Foundation (FAPESP), has given the opportunity for journals indexed in this database to use a more powerful online, electronic submission system. Therefore, soon the Journal of Applied Oral Science will use ScholarOne.

ScholarOne has been providing scholarly publishers, societies, and associations with online, flexible workflow solutions since the mid-1990s. It is the only peer review system with patented technology.

ScholarOne provides comprehensive workflow management systems for scholarly journals, books, and conferences. The web based applications enable publishers and societies to manage the submission, peer review, production, and publication process more efficiently and provides them with the intelligent information to help make strategic decisions.

Therefore, with ScholarOne we hope to be able to increase our profile among authors, and especially to decrease the time for the submission and review process.

We count on everyone's comprehension and patience during the transition from our current online submission system to ScholarOne.

Thank you for all the support.

Yours sincerely,

\section{Carlos F. Santos}

Editor-in-Chief

Journal of Applied Oral Science 